\title{
Heat Shock Proteins and the Cellular Response to Osmotic Stress
}

\author{
Franz-X. Beck, Rita Grünbein, Karin Lugmayr and Wolfgang Neuhofer
}

Physiologisches Institut der Universität München, München, Germany

\section{Key Words}

Heat shock proteins $\cdot$ HSP72 - MDCK cells $\cdot$ Renal medulla $\bullet$ Osmotic stress $•$ Urea $\cdot$ Antisense transfection

\begin{abstract}
In antidiuresis, the intrarenal distribution of HSP25/ 27, $\alpha$ B-crystallin, HSP72, OSP94 and HSP110 corresponds to the osmotic gradient between cortex and papilla: low amounts in the cortex and high values in the inner medulla and papilla. In addition, medullary HSP72 levels change appropriately with the diuretic state. Studies on MDCK cells suggest that, in the renal medulla in vivo, stressors, such as $\mathrm{NaCl}$ and low $\mathrm{pH}$, may act in concert to induce HSP72 expression. Urea, added to the medium at high concentrations (600 mM), causes the majority of MDCK cells to die. Prior exposure of these cells to hypertonic media ( $\mathrm{NaCl}$ addition), a maneuver that induces HSP72, protects the cells against the deleterious effects of high urea concentrations. Inhibition of HSP72 expression by stable antisense transfection or SB203580 treatment abolishes the beneficial effects of prior hypertonic stress. Conversely, overexpression of HSP72 under isotonic conditions by a dexamethasone-driven vector confers substantial resistance against subse-
\end{abstract}

\section{KARGER}

Fax +4161306 1234

E-Mail karger@karger.ch

www.karger.com
(C) 2000 S. Karger AG, Basel

1015-8987/00/0106-0303\$17.50/0

Accessible online at:

www.karger.com/journals/net quent exposure to high urea concentrations. Taken together these results suggest that also in the renal inner medulla, $\mathrm{NaCl}$-induced enhancement of HSP72 expression may help counteract the detrimental effects of high urea concentrations.

Copyright @ 2000 S. Karger AG, Basel

In most cells, changes in extracellular tonicity, i.e. in the concentration of solutes for which the cell membrane is poorly permeable (i.e. $\mathrm{NaCl}$ ), elicit an ordered and highly organized sequence of events that lead ultimately to osmotic adaptation. This process entails not only the loss or gain of inorganic and organic solutes in response to hypo- or hypertonic stress [1], but also a variety of complementary reactions affecting basic elements of cell life, such as reorganization of the cell structure (cytoskeleton), alterations in cell metabolism, cell growth and differentiation, and transcriptional activation or repression of specific genes [2].

In the mammalian organism, only the cells of the renal medulla are subject to substantial fluctuations in extracellular solute concentrations. In antidiuresis, medullary cells are confronted with high extracellular

Franz-X. Beck, M.D.

Physiologisches Institut der Universität

Pettenkoferstrasse 12, 80336 München (Germany)

Tel. +49 / 895996 534, Fax +49 / 895996532

E-Mail FX.Beck@physiol.med.uni-muenchen.de 
$\mathrm{NaCl}$ and urea concentrations, which then fall rapidly during the onset of water loading [3]. It is well established that the high extracellular $\mathrm{NaCl}$ concentrations in antidiuresis are balanced osmotically in the cell by small organic solutes ("organic osmolytes") [3], thus avoiding the negative effects of chronically elevated intracellular electrolyte concentrations. Whilst urea enters cells readily and need not to be compensated osmotically by non-urea osmolytes, high intracellular concentrations of urea perturb the structure and function of proteins. There is evidence suggesting that two of the organic osmolytes, betaine and glycerophosphorylcholine, not only contribute to osmotic balance but also counteract and mitigate these negative effects of high urea concentrations on cell function [4].

In the past few years it has become increasingly clear that accumulation of organic osmolytes is only one component of the osmotic response of medullary cells to high extracellular solute concentrations (reviewed in [3]). There is evidence that specific stress proteins, the heat shock proteins (HSPs), participate in the adaptation of these cells to an adverse environment. HSPs belong to a conserved class of proteins that are expressed constitutively by cells or/and induced by exposure to stressful conditions. According to their molecular weight, particular HSPs are classified into specific HSP families. Most HSPs are molecular chaperones: they interact transiently with unfolded or partially folded proteins and thereby assist in the correct folding of proteins, participate in intracellular protein trafficking, interact with cytoskeleton elements and may even help refolding misfolded proteins.

Evidence for the participation of HSPs in the osmotic stress response stems mainly from experiments on cell cultures. For instance, exposure to hypertonic media induces the expression of a variety of HSPs in renal epithelial cells [5-7]: in addition to HSP72, HSP25/27, the osmotic stress protein 94 (OSP94), and HSP110 are induced under such conditions. Further evidence for the contribution of HSPs to cellular osmoadaptation has been delivered by studies on the intrarenal distribution of various HSPs in the renal medulla [8-12]. These investigations showed that in kidneys producing a concentrated urine HSP25, $\alpha$ B crystallin, HSP72 and OSP94 display a distribution pattern corresponding to that of tissue solute concentrations: high, intermediate and low contents of these HSPs in inner medulla, outer medulla and cortex, respectively. This distribution pattern, however, is not observed for other members of the HSP family, such as the constitutively expressed HSP73 (also termed
HSC70) and HSP60 [11, 13]. In addition, the expression of HSP25 mRNA [14], HSP72 [8, 13], and OSP94 mRNA [10] changes appropriately with the diuretic state.

Apart from high extracellular $\mathrm{NaCl}$ concentrations, additional stress factors may affect expression of HSPs in the renal medulla. Since it is virtually impossible to study the effects on HSP expression of one specific stress factor independent of others in vivo, we chose MDCK cells as a model for examining the effects of various putative medullary stress factors, either individual or in combination, on HSP72 expression [15]. Exposure of MDCK cells to $300 \mathrm{mM}$ urea in the medium does not lead to a significant increase in HSP72 mRNA abundance or HSP72 content. When, however, the urea concentration of the medium is raised to $600 \mathrm{mM}$ most of the cells detach and die. Increasing the medium tonicity by addition of 50 or $150 \mathrm{mM} \mathrm{NaCl}$ causes both HSP72 mRNA abundance and HSP72 content to rise appropriately. Likewise, acidification of the medium to $\mathrm{pH} 6.5$ is associated with higher HSP72 mRNA abundance and HSP72 content. Moreover, the stimulation of HSP72 expression caused by addition of $50 \mathrm{mM} \mathrm{NaCl}$ is enhanced further by acidosis. However, reducing the medium $\mathrm{pH}$ to 6.5 in cultures that were exposed also to an additional $150 \mathrm{mM} \mathrm{NaCl}$ does not increase HSP72 expression further [15]. These observations suggest that in MDCK cells HSP72 expression is already maximal at a total $\mathrm{NaCl}$ concentration of about some $300 \mathrm{mM}(\sim 600$ $\mathrm{mOsm} / \mathrm{kg}$ ) in the medium.

As already noted, addition of $300 \mathrm{mM}$ urea to the medium does not affect HSP72 expression significantly. However, exposure of MDCK cells to acidic medium (pH 6.5) in combination with $300 \mathrm{mM}$ urea increases HSP72 content by a factor of 4 . This rise in HSP72 expression greatly exceeds that achieved with acidosis alone (Fig. 1). The enhancement of acidosis-induced HSP72 expression by urea may be due to amplification by urea of the destabilizing effect of increased proton concentrations on protein structure. Unfolded proteins are known to promote HSP72 expression.

Since in the renal papilla in vivo extracellular potassium concentrations may reach $40 \mathrm{mM}$ or more, we also examined the effect of increased extracellular potassium concentrations on HSP72 expression in MDCK cells. Although a rise in extracellular potassium concentration to $40 \mathrm{mM}$ roughly doubles HSP72 content, this increase does not exceed that achieved by the addition of sodium salts in equiosmolar concentrations [15]. This finding suggests that this rise in HSP72 expression is probably not due to specific effects of potassium but

Beck/Grünbein/Lugmayr/Neuhofer 
rather to an increase in extracellular tonicity. The observation that several medullary stress factors act synergistically on HSP72 expression suggests that the relatively high content of HSP72 in the inner medulla of chronically diuretic rats [13] is due to the concerted action of several, albeit weakly acting, stressors.

The signal cascade leading to enhanced transcription of the HSP72 gene following hypertonic stress is incompletely understood. Similar to other HSP genes, the 5'-region of the HSP72 gene includes so-called heat shock elements (HSEs) that are targets for specific transcription factors, the heat shock transcription factors (HSFs). Although increased binding of HSF to HSEs has been documented in 3T3 and HeLa cells after raising extracellular tonicity, this is not associated with enhanced expression of HSP72 in these cells [16, 17]. Hence, a causal role for HSF activation in hypertonicity-induced upregulation of HSP72 expression is uncertain. The observation that, in MDCK cells, SB203580, a potent inhibitor of p38 MAP kinase, significantly diminishes the upregulation of HSP72 expression after hypertonic stress suggests that this signal cascade participates in the modulation of HSP72 expression initiated by changes in extracellular tonicity $[18,19]$.

The functional role of hypertonicity-induced expression of HSP72 in renal medullary cells was studied in greater detail in MDCK cells. After exposure to hypertonic fluids medullary cells initially shrink and exhibit increased intracellular concentrations of monovalent inorganic electrolytes ("ionic strength"). Subsequently, organic osmolytes gradually accumulate and intracellular ionic strength normalizes pari passu. An early speculation was that the comparatively rapid rise in intracellular HSP72 content after hypertonic stress protects medullary cells against the adverse effects of elevated intracellular concentrations of inorganic electrolytes by bridging the gap between the rise in extracellular tonicity and the completion of osmolyte accumulation [5]. The observation, however, that even after chronic exposure to hypertonic stress, i.e. when osmotic adaptation is complete, intracellular HSP72 contents are still elevated, led us to suspect that this heat shock protein has additional functions. We then observed that MDCK cells adapted to high extracellular $\mathrm{NaCl}$ concentrations, and thus displaying high intracellular HSP72 levels, show increased resistance to high urea concentrations in the medium (600 $\mathrm{mM}$ ) [6]. To examine whether HSP72 may be responsible for this cytoprotection, hypertonicty-induced accumulation of HSP72 was inhibited. MDCK cells were exposed to SB203580 prior to exposure to elevated ex-

HSPs and Osmotic Stress

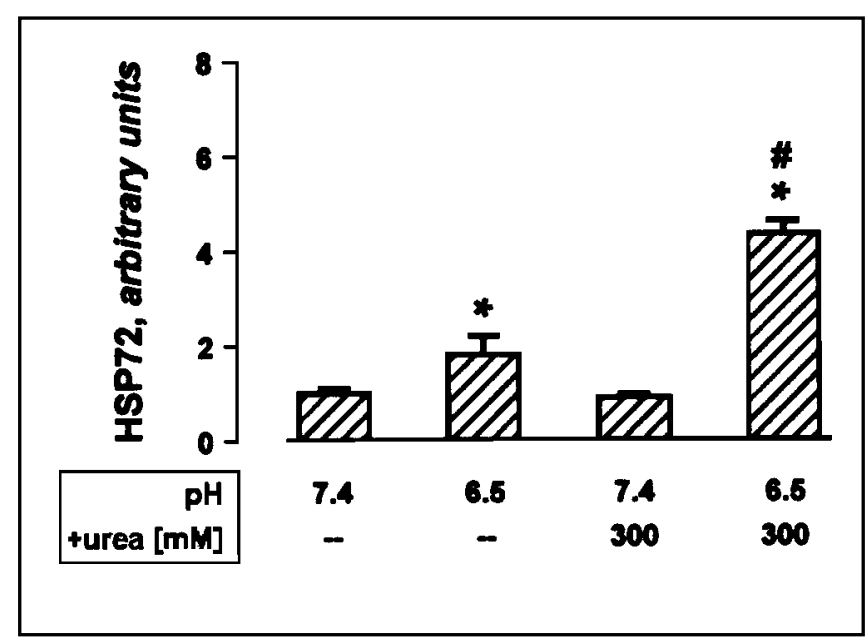

Fig. 1. Effect of low pH (6.5), high urea concentration (300 mM) and a combination of these conditions on HSP72 levels in MDCK cells. Means + SEM; * significantly different from controls; \# significantly different from MDCK cells exposed to $\mathrm{pH} 6.5$; data from [15].

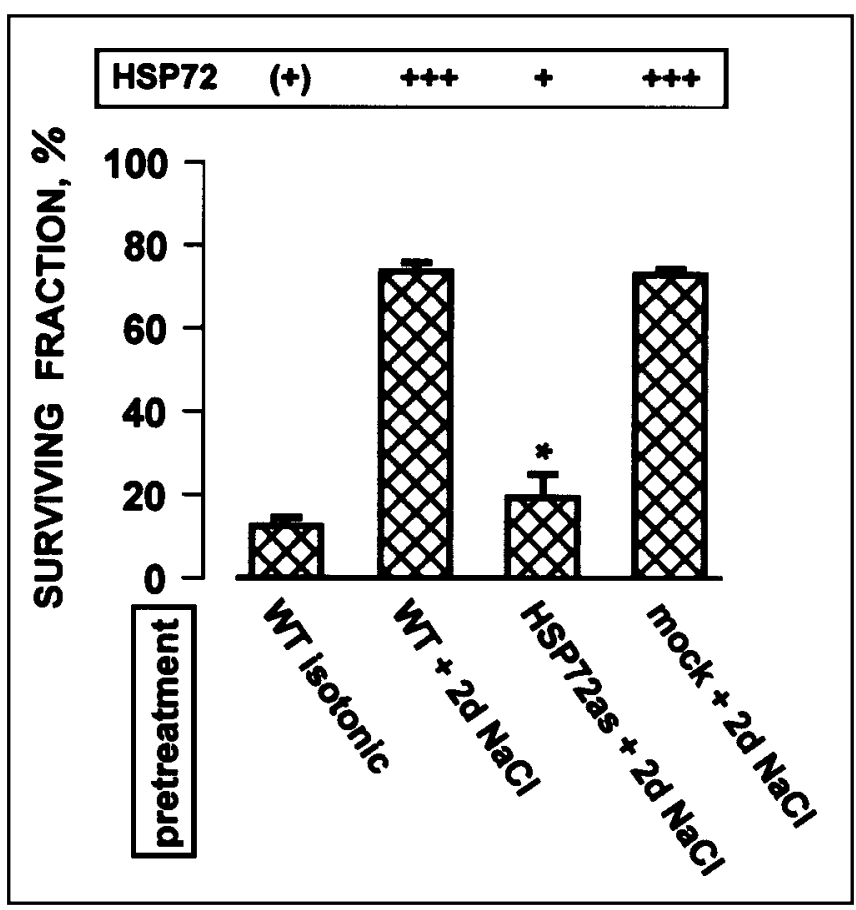

Fig. 2. HSP72 levels in MDCK cells (see the block above for illustration) correlate positively with resistance to high urea concentrations (600 mM); WT isotonic, wild-type MDCK cells kept in isotonic medium; $W T+2 d \mathrm{NaCl}$, wild-type MDCK cells pretreated for 2 days in hypertonic medium (addition of $150 \mathrm{mM}$ $\mathrm{NaCl}$ ); HSP72as $+2 d \mathrm{NaCl}$, MDCK cells stably transfected with HSP72 antisense construct and pretreated for 2 days in hypertonic medium; mock $+2 d \mathrm{NaCl}$, mock-transfected MDCK cells pretreated for 2 days in hypertonic medium; means + SEM; * significantly different from groups ,WT $+2 \mathrm{~d} \mathrm{NaCl}^{\text {“ }}$ and ,,mock $+2 \mathrm{~d} \mathrm{NaCl}^{\text {“; }}$ data from $[18,20]$.

Cell Physiol Biochem 2000;10:303-306 305 
tracellular $\mathrm{NaCl}$ concentrations [18, 19]. This maneuver effectively suppresses hypertonicity-induced induction of HSP72 and renders the cells subsequently susceptible to high urea concentrations [18]. Similar results are obtained when induction of HSP72 by hypertonic stress is impaired by stable transfection of MDCK cells with an HSP72-antisense construct. These cells do not respond to hypertonic stress with increased HSP72 production and are equally susceptible to a subsequent exposure to $600 \mathrm{mM}$ urea in the medium as sham-transfected cells kept in isotonic medium [18, 20] (Fig. 2). The view that increased intracellular HSP72 content protects MDCK cells against urea-induced apoptosis is further supported by experiments on MDCK cells transfected with a dex- amethasone-inducible vector encoding the complete HSP72 reading frame. After induction of HSP72 synthesis by dexamethasone these cells display improved resistance to the deleterious effects of high urea concentrations [21].

\section{Acknowledgements}

Work in the authors' laboratory was supported by the Deutsche Forschungsgemeinschaft

\section{References}

Lang F, Busch GL, Voelkl H: The diversity of volume regulatory mechanisms. Cell Physiol Biochem 1998;8:145.

2 Lang F, Busch GL, Ritter M, Voelkl H, Waldegger S, Gulbins E, Haeussinger D: Functional significance of cell volume regulatory mechanisms. Physiol Rev 1998;78:247-306. Beck FX, Burger-Kentischer A, Müller E: Cellular response to osmotic stress in the renal medulla. Pflügers Arch 1998;436:814-827.

4 Burg MB, Kwon ED, Peters EM: Glycerophosphocholine and betaine counteract the effect of urea on pyruvate kinase. Kidney Int 1996;50:S100-S104.

5 Cohen DM, Wasserman JC, Gullans SR: Immediate early gene and HSP70 expression in hyperosmotic stress in MDCK cells. Am J Physiol 1991;261:C594-C601. Neuhofer W, Müller E, BurgerKentischer A, Fraek ML, Thurau K, Beck FX: Pretreatment with hypertonic $\mathrm{NaCl}$ protects MDCK cells against high urea concentrations. Pflügers Arch 1998;435:407-414.

7 Santos BC, Chevaile A, Kojima R, Gullans SR: Characterization of the Hsp110/SSE gene family response to hyperosmolality and other stresses. Am J Physiol 1998;274:F1054-F1061. D, Wilkins W: In vivo and in vitro motic regulation of HSP-70 and prostaglandin synthase gene expression in kidney cells. Am J Physiol 1995;269:F854-F862.
Iwaki T, Iwaki A, Liem RK, Goldman JE: Expression of alpha B-crystallin in the developing rat kidney. Kidney Int 1991;40:52-56.

Kojima R, Randall J, Brenner BM, Gullans SR: Osmotic stress protein 94 (Osp94). A new member of the HSP110/SSE gene subfamily. J Biol Chem 1996;271:12327-12332.

Müller E, Neuhofer W, Ohno A, Rucker S, Thurau K, Beck FX: Heat shock proteins HSP25, HSP60, HSP72, HSP73 in isoosmotic cortex and hyperosmotic medulla of rat kidney. Pflügers Arch 1996;431:608-617.

Schober A, Müller E, Thurau K, Beck FX: The response of heat shock proteins 25 and 72 to ischaemia in different kidney zones. Pflügers Arch 1997; 434:292-299.

Müller E, Neuhofer W, BurgerKentischer A, Ohno A, Thurau K, Beck FX: Effects of long-term changes in medullary osmolality on heat shock proteins HSP25, HSP60, HSP72 and HSP73 in the rat kidney. Pflügers Arch 1998;435:705-712.

4 Medina R, Cantley L, Spokes K, Epstein FH. Effect of water diuresis and water restriction on expression of HSPs-27, -60 and -70 in rat kidney. Kidney Int 1996;50:1191-1194.

Neuhofer W, Müller E, Grünbein R, Thurau K, Beck FX: Influence of $\mathrm{NaCl}$, urea, potassium and $\mathrm{pH}$ on HSP72 expression in MDCK cells. Pflügers Arch 1999;439:195-200.
Alfieri R, Petronini PG, Urbani S, Borghetti AF: Activation of heat-shock transcription factor 1 by hypertonic shock in $3 \mathrm{~T} 3$ cells. Biochem $\mathrm{J}$ 1996;319:601-606.

17 Caruccio L, Bae S, Liu AYC, Chen KY: The heat-shock transcription factor HSF1 is rapidly activated by either hyper- or hypo-osmotic stress in mammalian cells. Biochem J 1997;327:341347.

18 Neuhofer W, Müller E, BurgerKentischer A, Fraek ML, Thurau K, Beck FX: Inhibition of $\mathrm{NaCl}$-induced heat shock protein 72 expression renders MDCK cells susceptible to high urea concentrations. Pflügers Arch 1999;437:611-616.

19 Sheikh-Hamad D, Di Mari J, Suki WN, Safirstein R, Watts BA, Rouse D: p38 kinase activity is essential for osmotic induction of mRNAs for HSP70 and transporter for organic solute betaine in Madin-Darby canine kidney cells. J Biol Chem 1998;273:1832-1837.

20 Beck FX, Neuhofer W, Müller E: Molecular chaperones in the kidney: distribution, putative roles, and regulation. Am J Physiol 2000; 279:F203-F215.

21 Neuhofer W, Grünbein R, Lugmayr K, Thurau K, Beck FX: Deaxamethasoneinduced, vector-driven overexpression of HSP72 protects MDCK cells against high urea. J Am Soc Nephrol 2000;11:20A. 